\title{
Examining Mechanical Properties of Recycled Aggregate Concrete
}

\author{
Ali Alsalman ${ }^{1}$, Jamal Khudair², Rahman S. Kareem³, Lateef Assi ${ }^{4}$, Canh N Dang ${ }^{5}$, José R. \\ Martí-Vargas ${ }^{6}$ \\ \{alialsalman609@gmail.com¹, ali.mohamed@almaaqal.edu.iq ${ }^{2}$, \\ rahman.s.kareem@edu.stu.iq ${ }^{3}$, lassi@email.sc.edu ${ }^{4}$,dncanh86@gmail.com ${ }^{5}$, \\ jrmarti@cst.upv.es $\left.{ }^{6}\right\}$ \\ Tatum-Smith-Welcher Engineers, Inc., 3100 S Market St., Rogers, AR 72758, USA ${ }^{1}$ \\ College of Engineering, Civil Engineering Department, Al Maaqal University, Basra, \\ Iraq $^{1}$ \\ College of Engineering, Civil Engineering Department, University of Basra, Basra, Iraq ${ }^{2}$ \\ University of Arkansas, Department of Civil Engineering, 4190 Bell Engineering Center \\ Fayetteville, AR 72701, USA ${ }^{3}$ \\ Department of Structure, Shatrah Technical Institute, Southern Technical University, \\ Shatrah, Dhi Qar, Iraq ${ }^{3}$ \\ Department of Civil and Environmental Engineering, University of South Carolina, \\ Columbia, $\mathrm{USA}^{4}$ \\ Department for Management of Science and Technology Development, Ton Duc Thang \\ University, Ho Chi Minh City, Vietnam ${ }^{5}$ \\ Faculty of Civil Engineering, Ton Duc Thang University, Ho Chi Minh City, Vietnam ${ }^{5}$ \\ Institute of Concrete Science and Technology (ICITECH), Universitat Politecnica de \\ Valencia, Valencia, Spain ${ }^{6}$
}

\begin{abstract}
Several mid-strength recycled aggregate concrete (RAC) combinations are developed in this study. Three groups are studied in the experimental section. Natural aggregate concrete (NAC) combinations, for example, employed 100 percent natural gravel aggregate. The second group (RAC-I) mixed natural gravel aggregate with recycled concrete aggregate (30 percent per total weight of coarse aggregates). The compressive strength of the parent concrete was 20-30 MPa. The third group (RAC-II) had a similar and larger percentage of recycled concrete aggregate replacement, ranging from $30 \%$ to $100 \%$. The compressive strength of the reference concrete was 30-40 MPa. The results showed that using 30\% recycled concrete aggregate had no effect on the workability and mechanical qualities of the concrete. At 112 days, the shrinkage of RAC-I combinations is 40 percent higher than that of NAC mixtures. Based on the results of the emissions analysis, RCA appears to be a viable alternative for reducing $\mathrm{CO} 2$ emissions.
\end{abstract}

Keywords: Sustainable Construction; Recycled Concrete Aggregate; Recycled Aggregate Concrete; Compressive Strength; Modulus Of Elasticity; Shrinkage; $\mathrm{CO}_{2}$ Emission.

\section{Introduction}

Construction and demolition wastes account for a large portion of solid wastes. The generation of these wastes has been increasing rapidly worldwide. The annual amount of wastes produced from construction and demolition is about 859 million tons in the EU [1] and about 230-530 million tons in the USA [2]. The most conventional method of disposing of these 
wastes has been through its disposal in landfills [3], which is a key contributor to environmental pollution. Some countries have established laws to prohibit or applied specific taxes for generating waste areas [3]. For decades in the construction industry, concrete has been the most popular material and consequently generated a major portion of demolition wastes; the annual consumption of concrete globally is approximately 10 billion tons [4]. It is well known that a typical concrete mix consists of ordinary Portland cement (OPC), water, and aggregates. The primary aggregates that are used in the concrete industry are sand and gravel (crushed rocks can be used instead of gravel). The continuous use of such materials might yield irreversible influence on the natural resources and environment as well (e.g., agricultural losses and rainforest devastations); globally, the construction industry uses approximately 48.3 billion tons of aggregates annually [5]; this number is anticipated to double over the next two decades if the rate of consumption stays the same [6]. Thus, recycling of demolished concrete has been recognized as a promising solution, not only to preserve the natural resources but also to offer a cleaner and sustainable practice (e.g., reduce the $\mathrm{CO}_{2}$ emission) for the construction industry [7].

Different kinds of solid wastes have been utilized as aggregates in concrete, such as recycled concrete aggregate (RCA), discarded tire rubber, and waste glass [8-10]. Among these materials, RCA gets a strong interest due to its readiness in a great amount, being available worldwide, and can partially or fully replace coarse and fine aggregates in new concrete [1113]. RCA is processed from crushed, graded inorganic materials that are sourced from construction and demolition debris, such as buildings, roads, bridges, and sometimes even from catastrophes like wars or earthquakes $[14,15]$. In terms of applications, RCA has been used in sub-base for road construction and permeable bases and concrete mixtures, such as sidewalks, curbs, bridge substructures, and building superstructures, concrete shoulders, and residential driveways $[3,16]$.

The utilization of RCA to develop recycled aggregate concrete (RAC) is locally oriented to fully reach its advantages. The aggregates are supposed to be collected, classified, and recycled within a small geographic region (e.g., a construction site, a city, or a town). This practice saves transportation costs, minimizes the burden on transportation infrastructures, and preserves energy. In this study, the researchers develop RAC mixtures from the demolition wastes of old buildings in the city of Basra. The wastes from the concrete account as the main source of construction and demolition wastes in Iraq due to the demolition from wars. The authors in this study aim to encourage design engineers in Basra to specify RAC in their design at least in nonstructural concrete by presenting several tests to examine the performance of RAC. On the other hand, this study validates the applicability of existing design code equations for predicting mechanical properties.

\section{Literature Review}

In terms of concrete workability, several studies have been performed to examine the effect of RCA. It was reported that as the RCA content increased, the workability decreased [6]. When RCA was used as coarse aggregate, 5\% mixing water was additionally needed for achieving workability similar to that of natural coarse aggregate. [17] stated that the concrete slump, which ranged from 50-100 $\mathrm{mm}$, was achievable by using superplasticizers. [18], however, observed that the initial slump of RAC was slightly affected by the relatively high-water absorption of RCA. On the other hand, the rate of slump loss increased as the water absorption capacity of 
RCA increased.

In terms of concrete mechanical properties, Younis and Mustafa [19] compared the mechanical properties of RAC to those of natural aggregate concrete (NAC). The investigated compressive strength ranged from 30.2 to $41 \mathrm{MPa}$ at 28 days. The compressive strength of RAC was approximately $84 \%$ of the NAC. On the other hand, the splitting tensile strength was $93 \%$ of the NAC. Similar findings were reported by Ismail et al. [20] and Yaba et al. [21]. Zhou and Chen [22], nevertheless, informed that the compressive and flexural strengths of RAC were similar and even exceeded the strengths of NAC. The observation was attributed to the high water absorption capacity of RCA, which resulted in the improvement of the bond strength between aggregate and cement paste matrix [22].

The parent concrete of RCA is influential to the service performance and durability of concrete. [23] evaluated the long-term mechanical properties of RAC containing coarse RCA. RCA produced from high-strength parent concrete (the compressive strength of parent concrete equal to $110 \mathrm{MPa}$ ) could result in slightly higher strength in comparison to conventional high-strength concrete for the same water/binder ratio $(w / b)$. However, the modulus of elasticity and splitting tensile strength of these high-strength RAC mixtures were similar to those of NAC at all ages. [24] pointed out that the utilization of RCA made from the parent concrete having a compressive strength of $50 \mathrm{MPa}$ or greater did not affect the mechanical properties of RAC.

The shape of RCA is influential since it affects the bond between the cement paste matrix and coarse aggregate. The experimental results reported by [25] showed that the shape (i.e., angular or round shape) of RCA and replacement level up to $100 \%$ of natural aggregate had a minimal impact on the compressive strength of RAC. On the other hand, the authors concluded that the splitting tensile strength of RAC was influenced by the RCA properties (i.e., shape, surface texture, and crushing procedure) and replacement level.

The incorporation level of RCA influences the mechanical properties of RAC. [26] found that concrete compressive strength of 30-45 MPa was achievable with $25 \%$ of coarse RCA using the same amount of cement as in NAC. The modulus of elasticity of RAC was lower in comparison to that of NAC, and the tensile strength of RAC might be higher than that of NAC. [13] prepared RAC with different levels of replacement of natural coarse aggregate by RCA $(20 \%, 40 \%, 60 \%$, $80 \%$, and $100 \%)$. The average reduction in compressive strength, splitting tensile strength, modulus of elasticity, and flexural strength were $10 \%, 14 \%, 11 \%$, and $9 \%$, respectively. Several studies stated that mechanical properties were not affected if RCA was incorporated by up to $30 \%$ of the natural coarse aggregate [11,27-29]. On the other hand, the study conducted by [30] indicated that replacing all coarse aggregate with $100 \%$ of RCA had minimal influence on the performance. In terms of the correlation between compressive strength and other mechanical properties such as modulus of elasticity, flexural strength, and splitting tensile strength, several studies have reported the findings [22, 31, 32].

In terms of concrete deformation, several studies demonstrated that the incorporation of RCA increased concrete shrinkage. This increase was attributed to the high deformability of the attached mortar of RCA [25]. [33] reported that concrete mixtures prepared with RCA produced from high-strength parent concrete had lower drying shrinkage and higher resistance to chlorideion penetration in comparison to the mixtures made with RCA produced from normal-strength parent concrete. The finding was confirmed by [34]. Also, [35] developed a drying shrinkage model for RAC containing both fine and coarse RCA. Test results showed that both fine and coarse RCA had a substantial influence on shrinkage, and the influence of fine RCA decreased with the content of coarse RCA increased. Moreover, [36] indicated that the internal curing effect of RCA delayed the development of free shrinkage at an early age. 


\section{Experimental Program}

\subsection{Materils Properties}

The cementitious material was the ordinary type I Portland cement [37]. Fine aggregate was natural gradation sand and used for all concrete mixtures [38]. Two types of coarse aggregate were used: natural gravel aggregate with a maximum aggregate size of $20 \mathrm{~mm}$ and RCA, as shown in Fig 1. The RCA was divided into two types based on the reference concrete: Type I obtained from a structural concrete source with 28-day compressive strength of 20-30 MPa, and Type II -obtained from a structural concrete source with 28-day compressive strength of 30-40 $\mathrm{MPa}$. Both types of RCA were sourced from demolition wastes of concrete buildings. The demolition wastes were crushed, sieved, and stored in buckets for ready use. The gradation curves, along with specific gravity (bulk oven-dried, bulk saturated surface dry, and apparent), water absorption, and unit weight of natural sand, natural gravel aggregate, and RCA are presented in Fig 2 and Table 1, respectively [39-41].
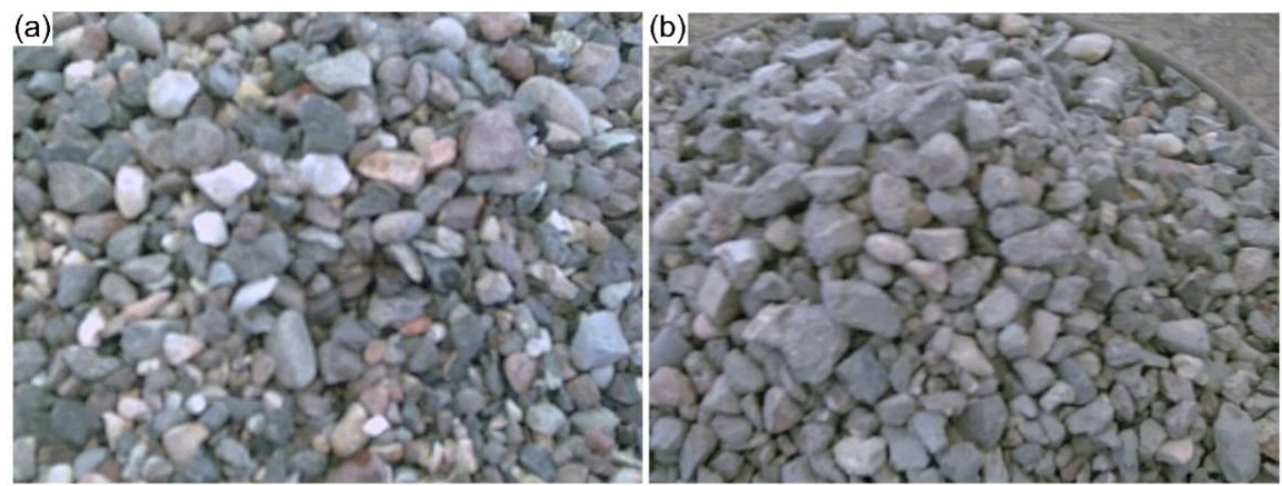

Fig 1. CoARse aggregates: (A) NATURAL GRAVEl AGgRegate (NGA) AND (B) RECyCled CONCRETE AGGREGATE (RECYCLED CONCRETE AGGREGATE TYPE I)

The specific gravity of RCA was about $63 \%$ of the natural gravel aggregate on average. Previous studies indicated that the specific gravity of RCA ranges from 1.91 to 2.70 [42]. The average water absorption capacity of RCA was $3.9 \%$, which is more than 4 times higher than that of natural gravel aggregate. Literature has reported values in the range of $0.5 \%$ to $14.75 \%$ [42]. On average, the unit weight of RCA was $84 \%$ of the natural gravel aggregate. The reduction in specific gravity and unit weight and the increase in water absorption capacity are attributed to the existence of loose paste in demolished construction wastes [11,43]. 
(a)

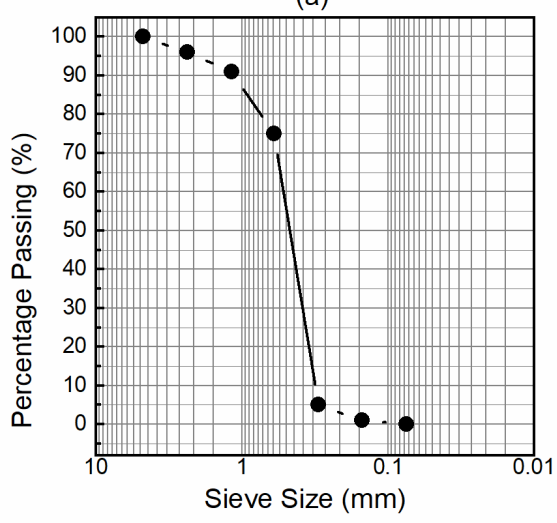

(c)

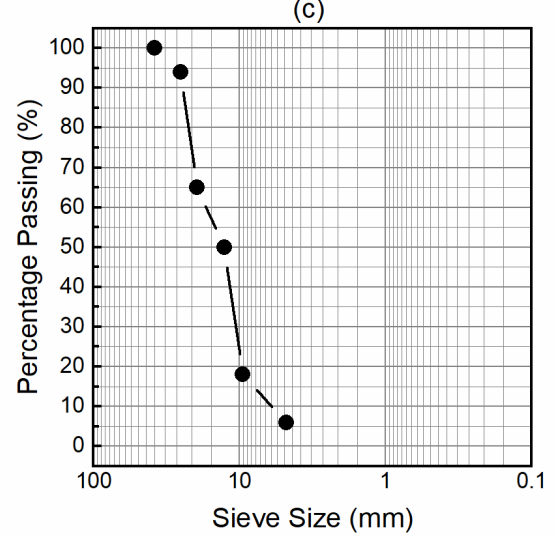

(b)

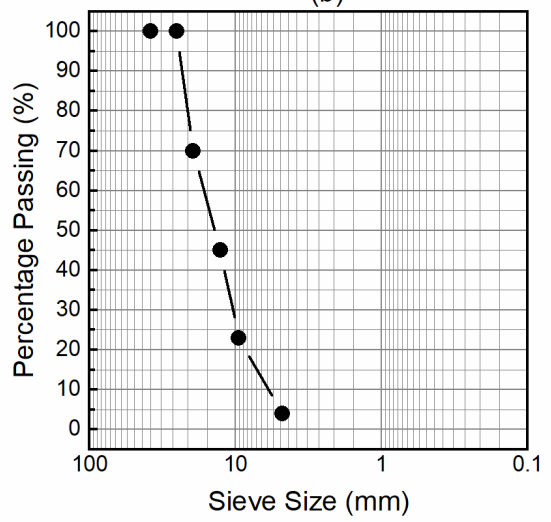

(d)

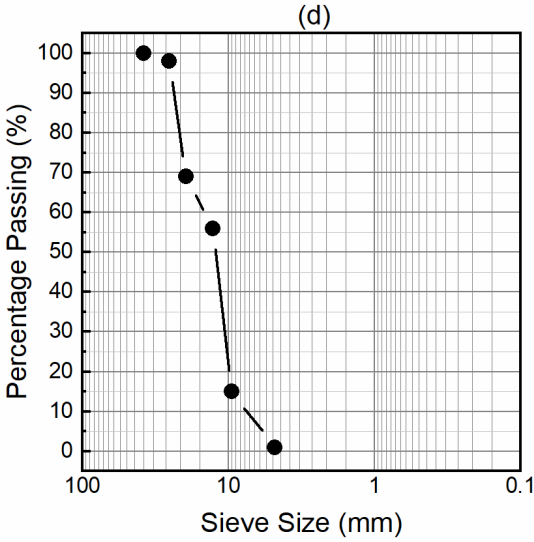

Fig 2. Gradation of AgGREGATEs: (A) NATURAl SAND, (B) NATURAL GRAVEL, (C) RECYCLED CONCRETE AGGREGATE TYPE I, AND (D) RECYCLED CONCRETE AGGREGATE TYPE II.

Table 1. Properties of aggregates

\begin{tabular}{|c|c|c|c|c|}
\hline Property & $\begin{array}{c}\text { Natural } \\
\text { Sand }\end{array}$ & $\begin{array}{c}\text { Natural } \\
\text { Coarse } \\
\text { Aggregate }\end{array}$ & RCA Type I & RCA Type II \\
\hline \multicolumn{5}{|l|}{ Specific gravity } \\
\hline $\begin{array}{ll}\text { Bulk oven- } \\
\text { dried }\end{array}$ & 2.61 & 2.65 & 1.64 & 1.66 \\
\hline Bulk SSD & 2.63 & 2.68 & 1.69 & 1.72 \\
\hline Apparent & 2.68 & 2.70 & 1.70 & 1.75 \\
\hline \multicolumn{5}{|l|}{ Absorption (\%) } \\
\hline & 1.29 & 0.90 & 3.83 & 3.90 \\
\hline \multicolumn{5}{|c|}{ Unit weight $\left(\mathrm{kg} / \mathrm{m}^{3}\right)$} \\
\hline Loose & 1400 & 1204 & 989 & 999 \\
\hline Compacted & 1478 & 1266 & 1073 & 1092 \\
\hline
\end{tabular}




\subsection{Mixture Proportions}

Table 2 summarizes the mixture proportions for three groups of concrete mixtures. For Group 1, mixtures NAC-1 to NAC-9 contained only natural aggregates (sand and natural gravel aggregates). Different $w / c$ ratios and aggregate to cement $(\mathrm{Agg} / \mathrm{C})$ ratios were used to cover a wide range of strength and workability. For Group 2, mixtures RAC-1 to RAC-9 investigated the effect of RCA Type I, which was incorporated by $30 \%$ of the total weight of coarse aggregate. The replacement ratio was selected based on the recommendation of previous research studies [11, 27, 28, 43]. For Group 3, three subgroups were considered to investigate the effect of RCA Type II, as follows: (i) mixtures RAC-10, 13, and 16 examined the influence of the parent concrete grade on compressive strength (for the same replacement ratio in Group $2-30 \%$ ); (ii) mixtures RAC-11, 14 and 17 examined the effect of 50\% replacement on concrete properties; and (iii) mixtures RAC-12, 15, and 18 examined the effect of $100 \%$ replacement on concrete properties. It should be noted that the content of cement is presented as an absolute amount, while the content of other concrete components is presented as a proportion to the cement content.

Table 2. Mixture proportions

\begin{tabular}{|c|c|c|c|c|c|c|c|c|c|}
\hline \multirow{3}{*}{$\begin{array}{c}\text { Mixtur } \\
\mathrm{e}\end{array}$} & \multirow{3}{*}{$\begin{array}{c}\text { Cement } \\
\mathrm{kg} / \mathrm{m}^{3}\end{array}$} & \multicolumn{5}{|c|}{ Weight Proportion } & \multicolumn{3}{|c|}{ Ratio } \\
\hline & & \multirow{2}{*}{$\begin{array}{l}\text { Portlan } \\
\text { d } \\
\text { cement }\end{array}$} & \multirow{2}{*}{$\begin{array}{l}\text { Natura } \\
1 \text { sand }\end{array}$} & \multirow{2}{*}{$\begin{array}{c}\text { Natural } \\
\text { coarse } \\
\text { aggregat } \\
\mathrm{e}\end{array}$} & \multicolumn{2}{|c|}{$\begin{array}{l}\text { Recycled } \\
\text { concrete } \\
\text { aggregate }\end{array}$} & \multirow{2}{*}{$w / c$} & \multirow{2}{*}{$\stackrel{A g g /}{C}$} & \multirow{2}{*}{$\begin{array}{c}\text { Recycle } \\
\text { concrete } \\
\text { aggregate / } \\
\text { Total } \\
\text { coarse } \\
\text { aggregate }\end{array}$} \\
\hline & & & & & Type I & $\begin{array}{l}\text { Type } \\
\text { II }\end{array}$ & & & \\
\hline \multicolumn{10}{|c|}{ Group 1. NAC (mixtures including natural gravel aggregate) } \\
\hline NAC-1 & 523 & 1 & 1 & 2 & - & - & 0.40 & 3 & - \\
\hline NAC-2 & 517 & 1 & 1 & 2 & - & - & 0.45 & 3 & - \\
\hline NAC-3 & 511 & 1 & 1 & 2 & - & - & 0.50 & 3 & - \\
\hline NAC-4 & 383 & 1 & 1.5 & 3 & - & - & 0.50 & 4.5 & - \\
\hline NAC-5 & 380 & 1 & 1.5 & 3 & - & - & 0.55 & 4.5 & - \\
\hline NAC-6 & 376 & 1 & 1.5 & 3 & - & - & 0.62 & 4.5 & - \\
\hline NAC-7 & 303 & 1 & 2 & 4 & - & - & 0.60 & 6 & - \\
\hline NAC-8 & 301 & 1 & 2 & 4 & - & - & 0.65 & 6 & - \\
\hline NAC-9 & 299 & 1 & 2 & 4 & - & - & 0.70 & 6 & - \\
\hline \multicolumn{10}{|c|}{ Group 2. RAC-I (mixtures including RCA Type I) } \\
\hline RAC-1 & 523 & 1 & 1 & 1.4 & 0.6 & - & 0.40 & 3 & 0.3 \\
\hline RAC-2 & 517 & 1 & 1 & 1.4 & 0.6 & - & 0.45 & 3 & 0.3 \\
\hline RAC-3 & 511 & 1 & 1 & 1.4 & 0.6 & - & 0.50 & 3 & 0.3 \\
\hline RAC-4 & 383 & 1 & 1.5 & 2.1 & 0.9 & - & 0.50 & 4.5 & 0.3 \\
\hline RAC-5 & 380 & 1 & 1.5 & 2.1 & 0.9 & - & 0.55 & 4.5 & 0.3 \\
\hline RAC-6 & 376 & 1 & 1.5 & 2.1 & 0.9 & - & 0.62 & 4.5 & 0.3 \\
\hline RAC-7 & 303 & 1 & 2 & 2.8 & 1.2 & - & 0.60 & 6 & 0.3 \\
\hline RAC-8 & 301 & 1 & 2 & 2.8 & 1.2 & - & 0.65 & 6 & 0.3 \\
\hline RAC-9 & 299 & 1 & 2 & 2.8 & 1.2 & - & 0.70 & 6 & 0.3 \\
\hline
\end{tabular}




\begin{tabular}{|c|c|c|c|c|c|c|c|c|c|}
\hline $\begin{array}{c}\text { RAC- } \\
10\end{array}$ & 517 & 1 & 1 & 1.4 & - & 0.6 & 0.45 & 3 & 0.3 \\
\hline $\begin{array}{c}\text { RAC- } \\
11\end{array}$ & 517 & 1 & 1 & 1 & - & 1 & 0.45 & 3 & 0.5 \\
\hline $\begin{array}{c}\text { RAC- } \\
12\end{array}$ & 517 & 1 & 1 & - & - & 2 & 0.45 & 3 & 1 \\
\hline $\begin{array}{c}\text { RAC- } \\
13\end{array}$ & 380 & 1 & 1.5 & 2.1 & - & 0.9 & 0.55 & 4.5 & 0.3 \\
\hline $\begin{array}{c}\text { RAC- } \\
14\end{array}$ & 380 & 1 & 1.5 & 1.5 & - & 1.5 & 0.55 & 4.5 & 0.5 \\
\hline $\begin{array}{c}\text { RAC- } \\
15\end{array}$ & 380 & 1 & 1.5 & - & - & 3 & 0.55 & 4.5 & 1 \\
\hline $\begin{array}{c}\text { RAC- } \\
16\end{array}$ & 301 & 1 & 2 & 2.8 & - & 1.2 & 0.65 & 6 & 0.3 \\
\hline $\begin{array}{c}\text { RAC- } \\
17\end{array}$ & 301 & 1 & 2 & 2 & - & 2 & 0.65 & 6 & 0.5 \\
\hline $\begin{array}{c}\text { RAC- } \\
18\end{array}$ & 301 & 1 & 2 & - & - & 4 & 0.65 & 6 & 1 \\
\hline
\end{tabular}

(Notes: NAC: Natural Aggregate Concrete; RAC: Recycled Aggregate Concrete; RCA: Recycled Concrete Aggregate; $\mathrm{Agg} / \mathrm{C}=$ coarse aggregate to cement ratio; $w / c=$ water to cement ratio).

\subsection{Concrete Testing}

The concrete was mixed using a tilting drum mixer. All dry materials were added and mixed for about one minute and then the water was added gradually to the mixer. The total mixing time was in a range of 3-5 minutes. The rheology of the concrete mixtures was evaluated by performing two tests: slump test and compacting factor test according to ASTM C143/C143M (2020) and [45], respectively. The slump test provides an approximate measurement of concrete consistency. In practice, the slump test is widely used as an indicator to evaluate consistency due to its simplification [46]. The compaction factor test, on the other hand, is more sensitive and accurate than the slump test and particularly beneficial for concrete mixtures with low workability and dry mixtures. The test can indicate significant differences in workability over a wide range since it is very sensitive and provides consistent results [47].

Cube specimens, $100 \mathrm{~mm} \times 100 \mathrm{~mm} \times 100 \mathrm{~mm}$, were cast to determine the compressive strength. Prism specimens, $100 \mathrm{~mm} \times 100 \mathrm{~mm} \times 500 \mathrm{~mm}$ were cast to measure flexure strength and drying shrinkage. Cylindrical specimens, $150 \mathrm{~mm}$ x $300 \mathrm{~mm}$, were cast to evaluate the splitting tensile strength and modulus of elasticity. The specimens were covered with damp canvas cloth and left in the laboratory for 24 hours. The specimens were then de-moulded and moist cured at $21^{\circ} \mathrm{C}$ until the day of testing. Compressive strength was determined at 7 and 28 days of age according to EN B 2019 12390-3 [48], in which the 28-day compressive strength is the strength of interest in this study. Flexure strength, splitting tensile strength, and modulus of elasticity was determined at 28 days of age according to [49], [50], and [51], respectively.

Concrete shrinkage was investigated by measuring the linear change (swelling and shrinkage) according to [52]. Several concrete prisms (100 $\mathrm{mm}$ x $100 \mathrm{~mm} \times 285 \mathrm{~mm})$ were cast and moist cured at $21^{\circ} \mathrm{C}$ for 14 days, then stored under laboratory general facilities conditions. Subsequent readings were recorded at intervals of 1 day, and at 3, 7, 10, and 14 days submerged in water, and after that at intervals of $3,7,14,21,28,42,56,70,84$, and 98 days stored in air at a temperature ranging from 16 to $30^{\circ} \mathrm{C}$. The test was terminated after 112 days. It should be noted that all tests were conducted for NAC and RAC-I mixtures, while the only compressive test was conducted for RAC-II mixtures since recycled concrete aggregate Type II was difficult to 
obtain. Most of the old buildings utilized concrete with compressive strength ranging from 20$30 \mathrm{MPa}$.

\section{Experimental Results and Discussions}

\subsection{Fresh Concrete Properties}

The measured slump and compacting factor result for NAC and RAC-I mixtures are shown in Figure 3. It can be noted that for a given $\mathrm{w} / \mathrm{c}$ and $\mathrm{Agg} / \mathrm{C}$ ratio, the RAC-I mixtures experienced lower workability, both in the measured slump and compacting factor. This observation is associated with the higher water absorption capacity of RCA (refer to Table 1), which results in a reduction in the net water content effective to the concrete workability. A similar finding is indicated by $[11,43]$. Furthermore, RCA particles have rougher surface texture and additionally contain old mortar attached to the particles in comparison to natural gravel aggregate indicated in Figure 1, thus more work is needed to overcome the increased internal friction [11].
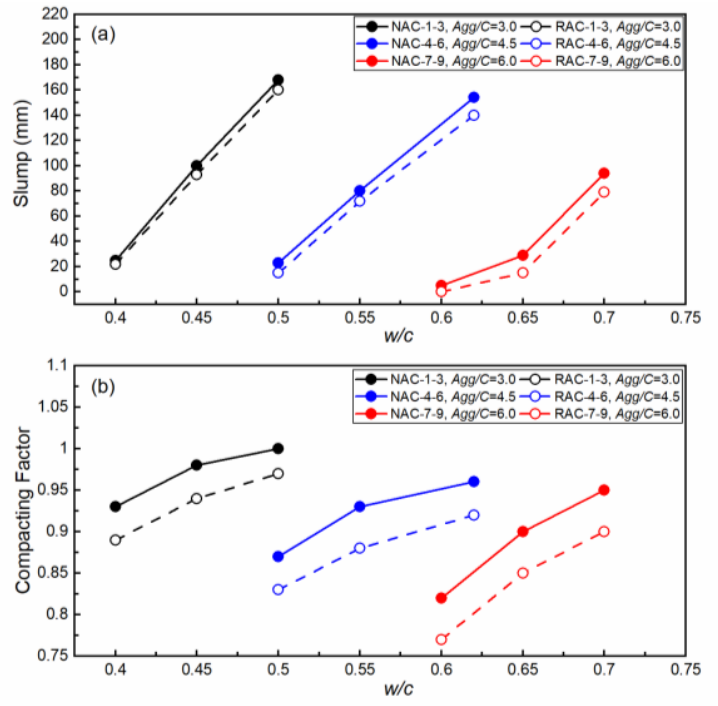

Fig 3. MEASURED (A) SLUMP AND (B) COMPACTING FACTOR

The effect of RCA types and replacement levels on the slump and compacting factor is indicated in Figure 4. For the same replacement level, the types of RCA have minimal influence on the slump and compacting factor, indicated by the results of the RAC-I and RAC-II mixture with $30 \%$ of RCA replacement. However, increasing the replacement level of RCA Type II from $30 \%$ to $50 \%$ reduced the slump and compacting factor by $22 \%$ and $3 \%$, respectively. Replacing all coarse aggregate with RCA Type II decreased slump and compacting factor by $56 \%$ and $5 \%$, respectively. This observation indicates that additional mixing and energy are needed for the concrete mixtures using 100\% coarse RCA. Matias et al. [25] stated that the low workability mixtures contained RCA can be improved to be comparable to natural aggregate mixtures by using superplasticizers with dosage ranges from 0.42 to $0.5 \%$ by weight of the cement. 

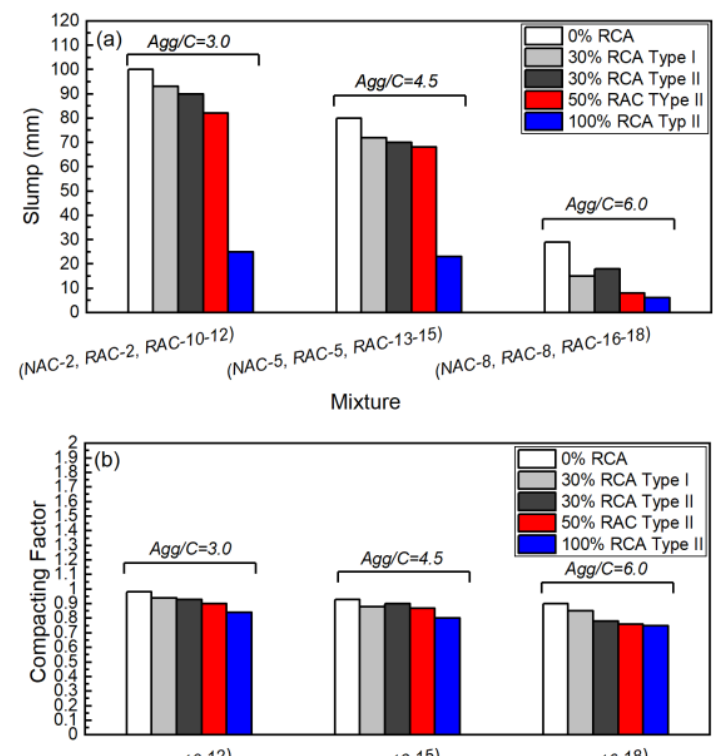

$$
\begin{aligned}
& \text { (NAC-2, RAC-2, RAC-10-12) } \\
& \text { (NAC-5, RAC-5, RAC-13-15) } \\
& \text { (NAC-8, RAC-8, RAC-16-18) }
\end{aligned}
$$

Fig 4. Effect of recycled concrete aggregate type and replacement level on (a) slump and (b) compacting

\subsection{Hardened concrete properties}

\subsubsection{Compressive strength}

Aggregate in concrete represents the unit weight, modulus of elasticity, and dimensional stability of concrete (i.e., shrinkage and creep) [53]. The measured compressive strength at 28 days of the age of the NAC and RAC-I mixtures is presented in Figure 5. Overall, the NAC and RAC-I experienced a similar trend regarding the concrete strength reduction when the $w / c$ ratio increased indicated by the dashed lines in the figure. This observation is apparent since the $w / c$ ratio plays an important role in controlling the concrete compressive strength. The amount of coarse aggregate is another factor governing the concrete strength. As indicated in Figure 5, the compressive strength decreases as the $A g g / C$ increases. In particular, the compressive strength of the concrete mixtures having $A g g / C$ of 6.0 is nearly a half in comparison to the strength of the mixtures having $A g g / C$ of 3.0. Figure 5 indicates the different effects of the RCA on the concrete compressive strength. For an $\mathrm{Agg} / \mathrm{C}$ ratio of 3.0, the RAC-I mixtures had lower compressive strength than comparable NAC mixtures. The average reduction was $4 \%$. This reduction may be attributed to the lower density and specific gravity of RCA as compared to natural gravel aggregate. A similar observation was found by [27, 28, 43]. As the aggregate content increased, RAC-I mixtures showed higher strength. The average increase was $12 \%$ and 20\% for an $\mathrm{Agg} / \mathrm{C}$ ratio of 4.5 and 6.0, respectively. The reason is related to the fact that RCA particles have an angular and rough surface texture and residual cementitious materials on the surface, which result in a better bond with cement paste matrix in comparison to natural gravel aggregate particles [24]. This observation is not in alignment with the one for $\mathrm{Agg} / \mathrm{C}$ of 3.0. 


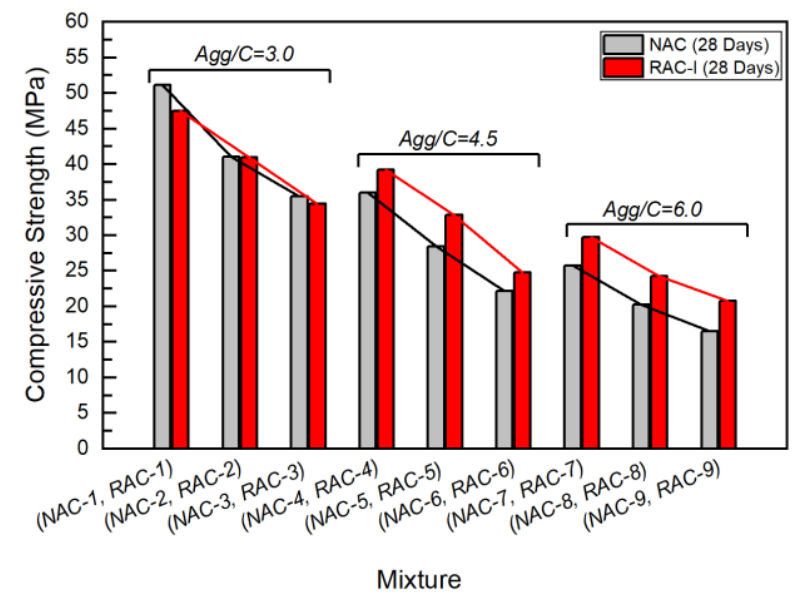

Fig 5. Measured 28-day compressive strength.

The effect of RCA type (Type I and Type II) and replacement level on compressive strength is presented in Figure 6. The RAC-II mixtures showed higher compressive strength than the comparable NAC and RAC-I mixtures. In comparison to the NAC mixtures, the increase was $20 \%$ on average. When the replacement of RCA Type II increased to $50 \%$ and $100 \%$, strength increased by $33 \%$ and $27 \%$ in comparison to the NAC mixtures, respectively. In comparison to the RAC-I mixtures, the strength increase was 7\%, 18\%, and 14\% for the replacement of $30 \%$, $50 \%$, and $100 \%$, respectively. This finding is consistent with earlier research studies regarding the effect of parent concrete strength on the compressive strength of RAC [23, 26, 36, 54, 55]. The compressive strength of the parent concrete affects the quality of the RCA. This is the possible reason why RAC-II yielded higher compressive strength than RAC-I.

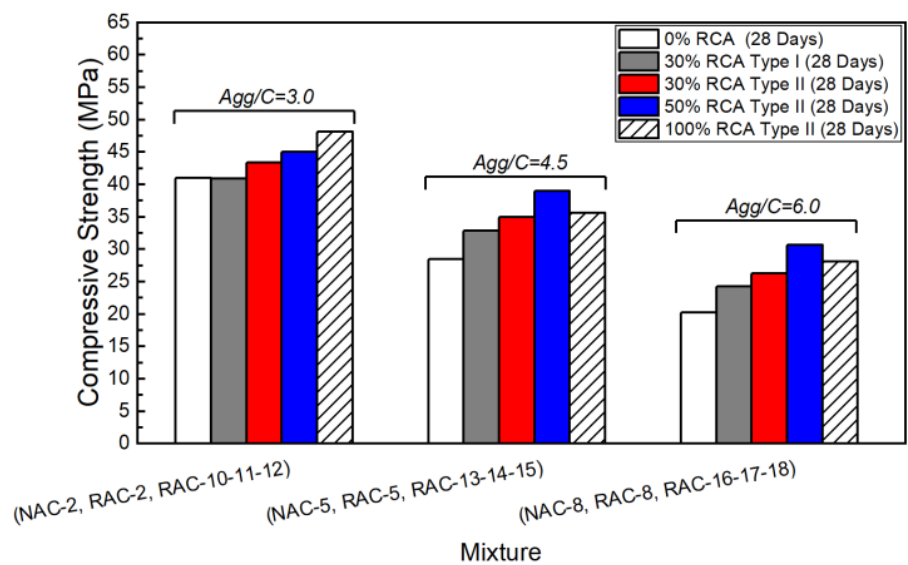

Fig 6. Effect of recycled concrete aggregate type and replacement level on compressive strength.

\subsubsection{Modulus of Rupture (Flexural Strength)}

Flexural strength depends on the aggregate type that affects the bond strength between cement paste matrix and coarse aggregate. The flexural strength results at 28-day of the age of the NAC and RAC-I mixtures are presented in Figure 7. For an $\mathrm{Agg} / \mathrm{C}$ ratio of 3.0, the NAC and RAC-I 
had similar flexural strength. The difference was $2 \%$ on average. The flexural strength of RACI mixtures was $12 \%$ and $22 \%$ higher than that of the NAC mixtures when the $\mathrm{Agg} / \mathrm{C}$ ratio increased to 4.5 and 6.0, respectively. These results are consistent with the findings by [26]. The high water absorption capacity of the adhered mortar that exists on the RCA surface can strengthen the bond between the coarse aggregate and cement paste matrix [24].

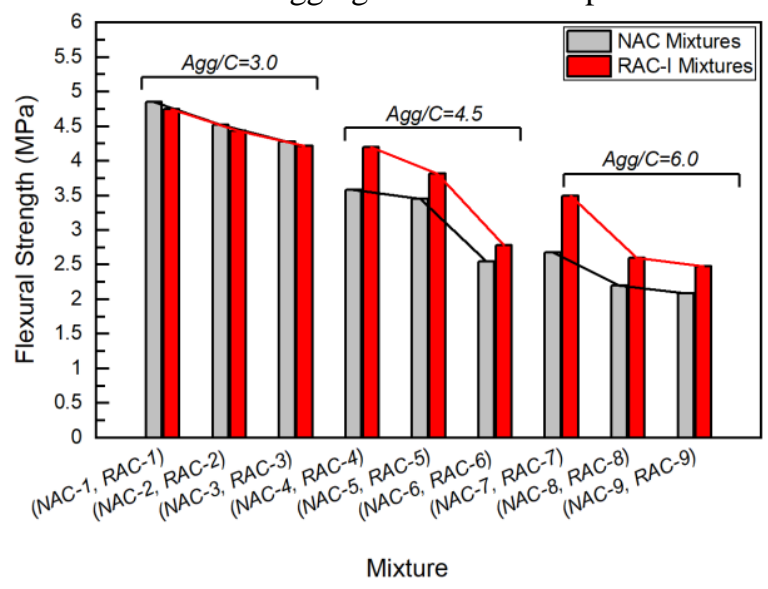

Fig 7. Flexural strength (Modulus of rupture)

The measured flexural strength of the NAC and RAC-I mixtures are compared to the predicted values by [56] as shown in Figure 8. Using the least-squares estimation method, the flexural strength of the NAC mixtures is represented by an equation $f_{b}=0.19\left(f^{\prime} c\right)^{0.84}$ with the coefficient of determination $R^{2}$ of 0.94 . As shown, the ACI 318 equation provides a conservative prediction of flexural strength for the concrete mixture having compressive strength equal to or greater than $32.5 \mathrm{MPa}$, where $32.5 \mathrm{MPa}$ as shown in Figure 8. For the mixtures having a compressive strength of less than $32.5 \mathrm{MPa}$, the ACI 318 equation overestimates the experimental values, which is unconservative in design. Similarly, the flexural strength of the RAC-I mixtures is represented by the equation $f b=0.17\left(f^{\prime} c\right)^{0.88}$ with the coefficient of determination $R^{2}$ of 0.95 . The ACI 318 equation provides a conservative prediction for the mixtures. 

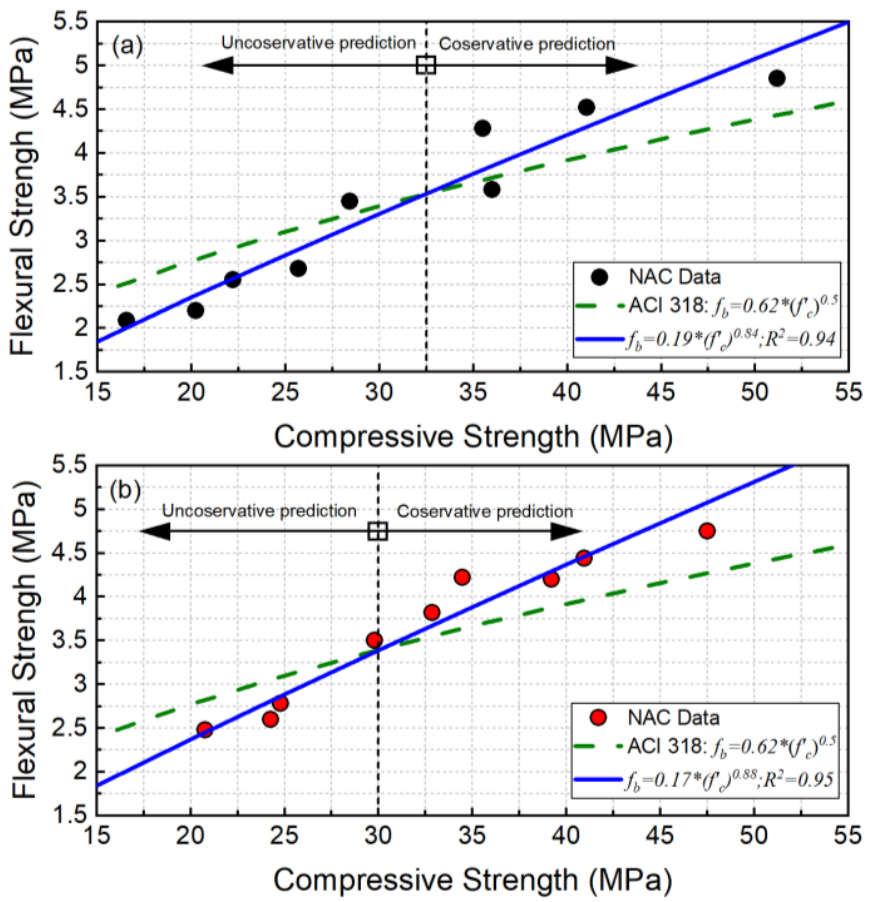

Fig 8. Flexural strength and compressive strength for (a) NAC and (b) RAC-I.

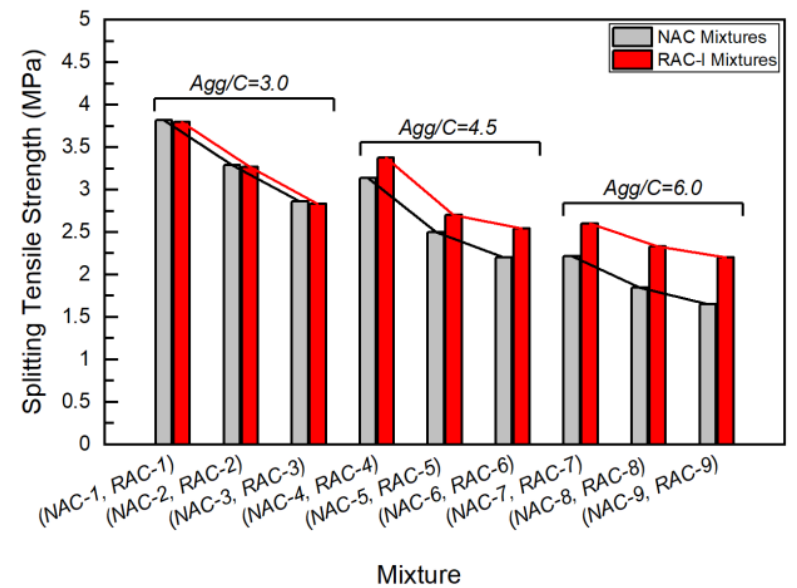

Fig 9. Splitting tensile strength.

\subsubsection{Strength of Splitting Tensile}

Like the flexural strength, the aggregate type can influence the tensile strength. The splitting tensile strength results at 28-day of the age of the NAC and RAC-I mixtures are presented in Figure 9. For an $\mathrm{Agg} / \mathrm{C}$ ratio of 3.0, the RAC-I mixtures yielded approximately the same strength as the NAC mixtures. As the $\mathrm{Agg} / \mathrm{C}$ ratio increased to 4.5 and 6.0, the RAC-I mixtures showed higher tensile strength by $10 \%$ and $25 \%$ in comparison to the NAC mixtures, respectively. The enhancement in the bond between the new cement matrix to the old one present on the surface of RCA particles is the source of the observation, which is like the one observed in the flexural 
strength results. The verification of the experimental values against the design code is presented in Figure 10. Using the least-squares estimation method, the experimental data of the NAC and RAC-I mixtures are represented by $f_{t}=0.20\left(f^{\prime} c\right)^{0.76}$ and $f_{t}=0.31\left(f^{\prime} c\right)^{0.64}$ with the coefficient of determination $R^{2}$ of 0.98 and 0.94 , respectively. As shown in the figure, on average, the ACI 318 equation overestimates the tensile strength of all NAC and RAC-I mixtures.
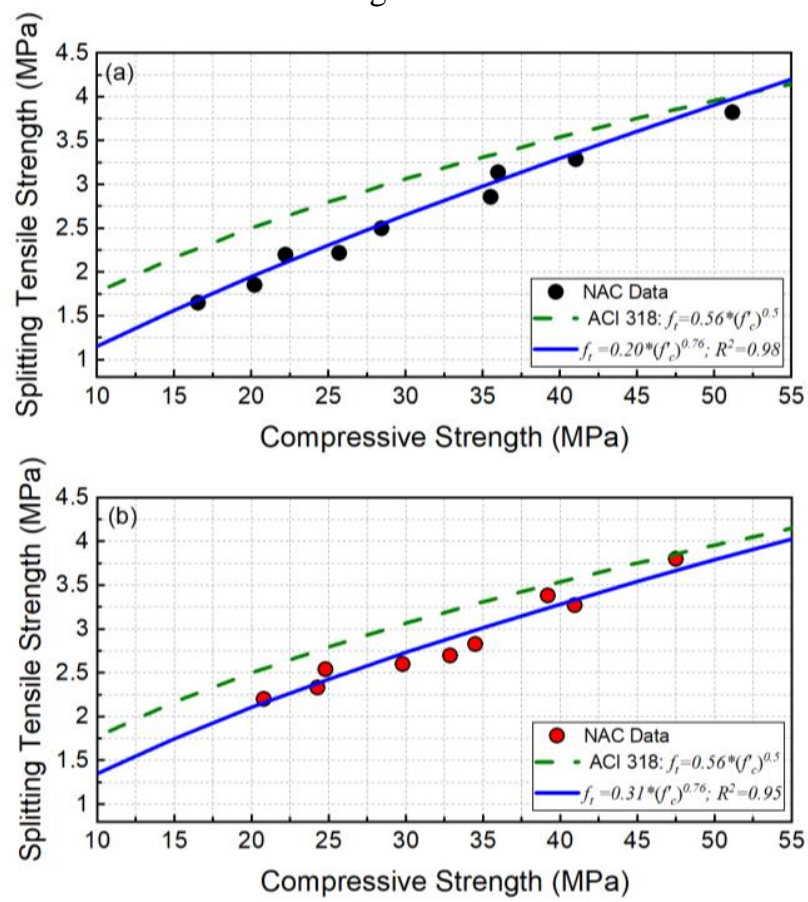

Fig 10. Relationship between splitting tensile strength and compressive strength (a) NAC and (b).

\subsubsection{Modulus of Elasticity}

The aggregate type is influencing the modulus of elasticity of concrete [53]. The modulus of elasticity test results of the NAC and RAC-I mixtures are presented in Figure 11. For an $\mathrm{Agg} / \mathrm{C}$ ratio of 3.0, the RAC-I mixtures showed a lower modulus of elasticity in comparison to the NAC mixtures. The reduction was about $6 \%$. The observed reduction is consistent with previous findings $[11,22]$. Previous studies indicated that $30 \%$ incorporation of RCA by the total weight of coarse aggregate has minimal influence on the modulus of elasticity of RAC-I [11, 27-29, 43]. The minimal effect can be attributed to the fact that the modulus of elasticity. The concrete modulus of elasticity and concrete compressive strength is depicted in Figure 12. As can be observed, the ACI 318 equation captures the variation trend of the experimental data of the NAC and RAC-I mixtures. The experimental data of the NAC and RAC-I mixtures are represented by equation $\mathrm{Ec}=4520\left(\mathrm{f}_{\mathrm{c}}\right)^{0.5}$ and $4520\left(\mathrm{f}_{\mathrm{c}}\right)^{0.56}$ with the coefficient of determination $\mathrm{R}^{2}$ of 0.99 and 0.97 , respectively. On average, the ACI 318 equation overestimates the measured modulus of elasticity of the NAC and RAC-I mixtures by 5\% and 14\%, respectively. The lower density of RCA led to a reduction in stiffness. Furthermore, the natural gravel aggregate might participate in decreasing elasticity of concrete [28], at which the ACI 318 equation provides a fairly accurate prediction. 


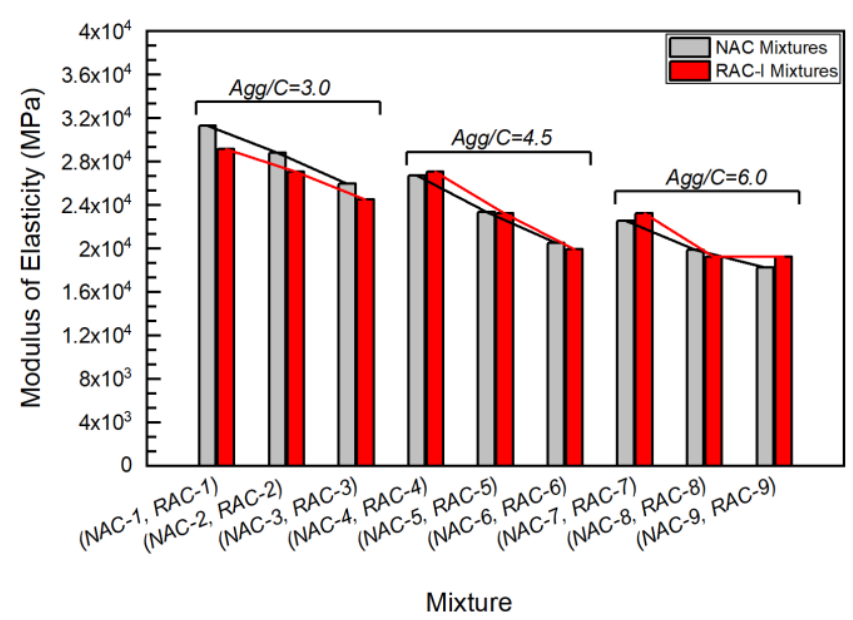

Fig 11. Modulus of elasticity.
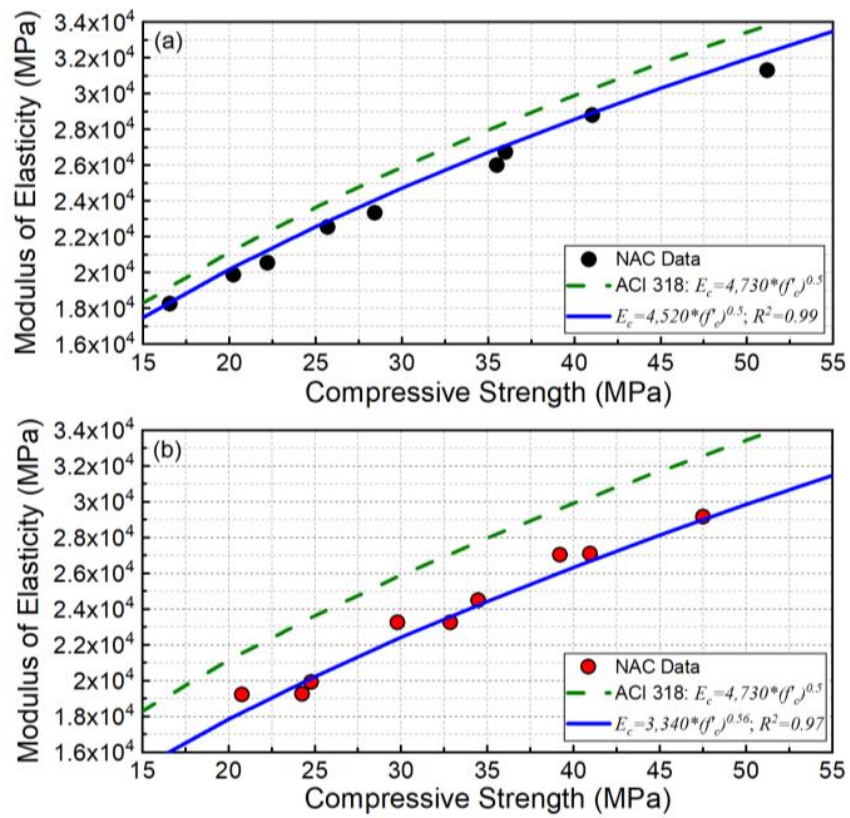

Fig 12. ELASTICITY AND COMPRESSIVE STRENGTH FOR (A) NAC AND (B) RAC-I.

\subsubsection{Linear Change (Swelling and Shrinkage)}

The error bars are based on a 95\% confidence interval. On average, the expansion of the RACI mixtures at 3, 7, 10, and 14 days is $130 \%, 121 \%, 107 \%$, and $116 \%$ higher than that of the NAC mixtures, respectively. The RAC-I mixtures exhibited higher shrinkage in comparison to the NAC mixtures regardless of $A g g / C$ and $w / c$ ratios. The difference in shrinkage between NAC and RAC-I mixtures tends to be consistent over time. The shrinkage of the RAC-I mixtures was $40 \%$ higher. This observation is accounted for the higher porosity and water absorption 
generated by the existing mortar present on the surface of RCA particles [25].

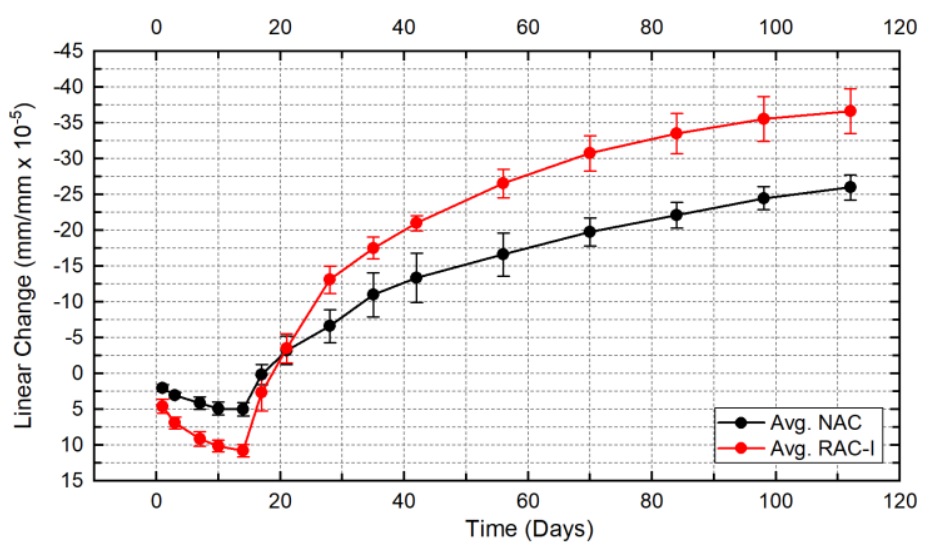

Fig 13. Average LiNEAR CHANGE: SWELLING AND SHRINKAGE FOR NAC AND RAC-I.

\subsection{6 $\mathrm{CO}_{2}$ Emission of Concrete Mixtures}

Because of the energy consumption during the process of manufacturing the raw materials of concrete, $\mathrm{CO}_{2}$ is emitted into the atmosphere. Table 3 presents the resultant $\mathrm{CO}_{2}$ emission of each component of the concrete.

Table 3. Emission factors of materials ${ }^{1}$

\begin{tabular}{|l|c|c|}
\hline \multicolumn{1}{|c|}{ Material } & $\mathrm{kg}-\mathrm{CO}_{2} / \mathrm{kg}$ & Reference \\
\hline OPC & 0.840 & Sanjuán et al. [57] \\
\hline Natural sand & 0.0048 & Hammond et al. [58] \\
\hline Natural coarse aggregate & 0.0048 & Hammond et al. [58] \\
\hline $\begin{array}{l}\text { Recycled concrete aggregate } \\
\text { (RCA-I \& RCA-II) }\end{array}$ & 0.0020 & $\begin{array}{c}\text { Alnahhal et al. [7] and García-Segura et } \\
\text { al. [59] }\end{array}$ \\
\hline
\end{tabular}

${ }^{1}$ value of emission does not account for the emission resulted from transportation.

Table 3 summarizes the $\mathrm{CO}_{2}$ emission for all concrete mixtures for one cubic meter of concrete as the functional unit. The highest $\mathrm{CO}_{2}$ emission was observed with NAC-1 $\left(447 \mathrm{~kg}-\mathrm{CO}_{2} / \mathrm{m}^{3}\right)$ and the lowest was RAC-18 $\left(257 \mathrm{~kg}-\mathrm{CO}_{2} / \mathrm{m}^{3}\right)$. That $\mathrm{OPC}$ is the main contributor to the emission of all mixtures. On the other hand, the $100 \%$ replacement of natural coarse aggregate by RCAII yielded an average reduction of the emission by $1.3 \%$.

Table 4. Emission for one cubic of concrete.

\begin{tabular}{|c|c|c|c|c|c|c|}
\hline \multicolumn{7}{|c|}{ Emission $\mathrm{kg}-\mathrm{CO}_{2} / \mathrm{m}^{3}$} \\
\hline Mixture & Cement & Sand & Gravel & RCA-I & RCA-II & Total \\
\hline NAC-1 & 439 & 3 & 5 & 0 & 0 & 447 \\
\hline NAC-2 & 434 & 2 & 5 & 0 & 0 & 442 \\
\hline NAC-3 & 429 & 2 & 5 & 0 & 0 & 436 \\
\hline NAC-4 & 322 & 3 & 6 & 0 & 0 & 330 \\
\hline NAC-5 & 319 & 3 & 6 & 0 & 0 & 328 \\
\hline NAC-6 & 316 & 3 & 5 & 0 & 0 & 324 \\
\hline NAC-7 & 255 & 3 & 6 & 0 & 0 & 263 \\
\hline NAC-8 & 253 & 3 & 6 & 0 & 0 & 262 \\
\hline
\end{tabular}




\begin{tabular}{|l|l|l|l|l|l|l|}
\hline NAC-9 & 251 & 3 & 6 & 0 & 0 & 260 \\
\hline RAC-1 & 439 & 2 & 3 & 1 & 0 & 445 \\
\hline RAC-2 & 434 & 2 & 3 & 1 & 0 & 440 \\
\hline RAC-3 & 429 & 2 & 3 & 1 & 0 & 435 \\
\hline RAC-4 & 322 & 2 & 3 & 1 & 0 & 328 \\
\hline RAC-5 & 319 & 2 & 3 & 1 & 0 & 326 \\
\hline RAC-6 & 316 & 2 & 3 & 1 & 0 & 322 \\
\hline RAC-7 & 255 & 3 & 4 & 1 & 0 & 261 \\
\hline RAC-8 & 253 & 3 & 4 & 1 & 0 & 260 \\
\hline RAC-9 & 251 & 3 & 4 & 1 & 0 & 258 \\
\hline RAC-10 & 434 & 2 & 3 & 0 & 1 & 440 \\
\hline RAC-11 & 434 & 2 & 2 & 0 & 1 & 440 \\
\hline RAC-12 & 434 & 2 & 0 & 0 & 2 & 438 \\
\hline RAC-13 & 319 & 2 & 3 & 0 & 1 & 326 \\
\hline RAC-14 & 319 & 2 & 2 & 0 & 1 & 325 \\
\hline RAC-15 & 319 & 2 & 0 & 0 & 2 & 323 \\
\hline RAC-16 & 253 & 3 & 4 & 0 & 1 & 260 \\
\hline RAC-17 & 253 & 3 & 26 & 0 & 1 & 282 \\
\hline RAC-18 & 253 & 2 & 0 & 0 & 2 & 257 \\
\hline
\end{tabular}

To examine the efficiency of each mixture, the ratio of the $\mathrm{CO}_{2}$ emission to the compressive strength at the age of 28 days is considered as shown in Figure 14. It can be noticed that RAC16 is the most efficient $\left(5.4 \mathrm{~kg}-\mathrm{CO}_{2} / \mathrm{MPa}\right)$ which is $50 \%$ less compared to the corresponding with natural coarse aggregates (mixture NAC-8). In general, for medium-high strength concrete, mixtures with $30 \%$ of RCA-I showed less efficiency compared to NAC mixtures (NAC-1 and RAC-1, NAC-2 and RAC-2, NAC-3 and RAC-3). For medium and low strengths, RAC mixtures with $30 \%$ of RCA-I were more efficient; efficiency was $14 \%$ higher than NAC mixtures. Similarly, mixtures contained $50 \%$ and $100 \%$ of RCA-II showed higher efficiency with low strength concrete mixtures; the efficiency was $44 \%$ and $29 \%$, respectively compared to NAC mixtures.

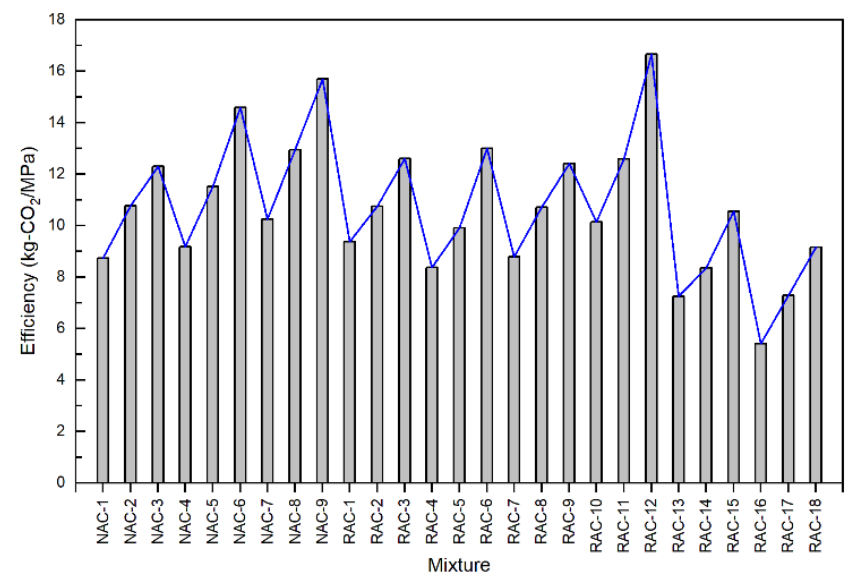

Fig 14. The EFFICIENCY OF CONCRETE MIXTURES. 


\section{Conclusion}

The following list are the conclusions for the results:

1. RAC mixtures batched with $30 \%$ recycled concrete aggregate show lower workability than the NAC mixtures. The difference in workability between the two types of mixtures is more apparent as the $\mathrm{Agg} / \mathrm{C}$ ratio increases.

2. For an $A g g / C$ ratio of 3.0, the NAC mixtures show marginally higher compressive strength, flexural strength, splitting tensile strength, and modulus of elasticity as compared to those of the RAC mixtures. The average increase was $3 \%, 2 \%, 1 \%$, and $7 \%$, respectively.

3. For an $\mathrm{Agg} / \mathrm{C}$ ratio of either 4.5 or 6.0 , the NAC mixtures show lower compressive strength, flexural strength, and splitting tensile strength as compared to those of the RAC mixtures. The average reduction was $10 \%, 16 \%$, and $17 \%$, respectively. The modulus of elasticity, however, did not follow the same trend; both NAC and RAC mixtures show approximately the same values for an $\mathrm{Agg} / \mathrm{C}$ ratio of 4.5 and 6.0.

4. Using RCA originated from a parent concrete with compressive strength of 30-40 MPa enhanced the RAC compressive strength by approximately $7 \%$ as compared to RCA originated from a parent concrete with compressive strength of 20-30 MPa at the same level of replacement. In comparison to NAC, the enhancement was $20 \%$ on average.

5. ACI 318 overestimates the measured splitting tensile strength and modulus of elasticity for all RAC and NAC mixtures. Regarding the flexural strength, ACI 318 overestimates the NAC and RAC mixtures having compressive strength less than $32.5 \mathrm{MPa}$ and $30 \mathrm{MPa}$, respectively. Otherwise, the ACI 318 provides a conservative prediction.

6. The incorporation of $30 \%$ of recycled concrete aggregate increased swelling and shrinkage. The difference in shrinkage between the RAC and NAC mixtures tended to be consistent over time. At the age of 112 days, the difference was about $40 \%$.

7. $\mathrm{OPC}$ is the main contributor to the $\mathrm{CO} 2$ emission of concrete, and it is responsible for approximately $97 \%$ of the total $\mathrm{CO}_{2}$ emission.

8. The use of RCA can reduce the $\mathrm{CO}_{2}$ emission generated from one cubic meter of concrete for low-strength concrete mixtures. As an average, mixtures contained 30\%, 50, and 100\% showed $14 \%, 44 \%$, and $29 \%$, respectively.

\section{References}

[1] European Commission. Directorate General for Internal Market, Industry, Entrepreneurship and SMEs. Development and implementation of initiatives fostering investment and innovation in construction and demolition waste recycling infrastructure. LU: Publications Office, https://data.europa.eu/doi/10.2873/11837 (2018, accessed 13 May 2021).

[2] United States Environmemtal Protection Agency. The State of the Practice of Construction and Demolition Material Recovery-Final Report. EPA/600/R-17/231, https://nepis.epa.gov/Exe/ZyPDF.cgi/P100SSJP.PDF?Dockey=P100SSJP.PDF (2017).

[3] Malešev M, Radonjanin V, Marinković S. Recycled concrete as aggregate for structural concrete production. Sustainability 2010; 2: 1204-1225.

[4] Aprianti S E. A huge number of artificial waste material can be supplementary cementitious material (SCM) for concrete production - a review part II. Journal of Cleaner Production 2017; 142: 41784194.

[5] Bostanci SC, Limbachiya M, Kew H. Use of recycled aggregates for low carbon and cost effective concrete construction. Journal of Cleaner Production 2018; 189: 176-196. 
[6] Visintin P, Xie T, Bennett B. A large-scale life-cycle assessment of recycled aggregate concrete: The influence of functional unit, emissions allocation and carbon dioxide uptake. Journal of Cleaner Production 2020; 248: 119243.

[7] Alnahhal MF, Alengaram UJ, Jumaat MZ, et al. Assessment on engineering properties and CO2 emissions of recycled aggregate concrete incorporating waste products as supplements to Portland cement. Journal of Cleaner Production 2018; 203: 822-835.

[8] Kim J-H, Sung J-H, Jeon C-S, et al. A study on the properties of recycled aggregate concrete and its production facilities. Applied Sciences 2019; 9: 1935.

[9] Thomas BS, Gupta RC. Properties of high strength concrete containing scrap tire rubber. Journal of Cleaner Production 2016; 113: 86-92.

[10] Letelier V, Henríquez-Jara BI, Manosalva M, et al. Combined use of waste concrete and glass as a replacement for mortar raw materials. Waste Management 2019; 94: 107-119.

[11] Rahal K. Mechanical properties of concrete with recycled coarse aggregate. Building and environment 2007; 42: 407-415.

[12] Verma SK, Ashish DK. Mechanical behavior of concrete comprising successively recycled concrete aggregates. Advances in concrete construction 2017; 5: 303-311.

[13] Hamad BS, Dawi AH. Sustainable normal and high strength recycled aggregate concretes using crushed tested cylinders as coarse aggregates. Case Studies in Construction Materials 2017; 7: 228 239.

[14] McNeil K, Kang TH-K. Recycled concrete aggregates: A review. International journal of concrete structures and materials 2013; 7: 61-69.

[15] Zhang J, Shi C, Li Y, et al. Performance enhancement of recycled concrete aggregates through carbonation. Journal of Materials in Civil Engineering 2015; 27: 04015029.

[16] Gupta N, Kluge M, Chadik PA, et al. Recycled concrete aggregate as road base: Leaching constituents and neutralization by soil Interactions and dilution. Waste Management 2018; 72: 354361.

[17] Somna R, Jaturapitakkul C, Chalee W, et al. Effect of the Water to Binder Ratio and Ground Fly Ash on Properties of Recycled Aggregate Concrete. J Mater Civ Eng 2012; 24: 16-22.

[18] Yang K-H, Chung H-S, Ashour AF. Influence of Type and Replacement Level of Recycled Aggregates on Concrete Properties.

[19] Younis KH, Mustafa SM. Feasibility of Using Nanoparticles of SiO2 to Improve the Performance of Recycled Aggregate Concrete. Advances in Materials Science and Engineering 2018; 2018: e1512830.

[20] Ismail A, Younis KH, Maruf S. Recycled Aggregate Concrete Made with Silica Fume: Experimental Investigation. Civil Engineering and Architecture 2020; 8: 1136-1143.

[21] Yaba HK, Naji HS, Younis KH, et al. Compressive and flexural strengths of recycled aggregate concrete: Effect of different contents of metakaolin. Materials Today: Proceedings. Epub ahead of print 10 February 2021. DOI: 10.1016/j.matpr.2021.01.164.

[22] Zhou C, Chen Z. Mechanical properties of recycled concrete made with different types of coarse aggregate. Construction and Building Materials 2017; 134: 497-506.

[23] Gholampour A, Ozbakkaloglu T. Time-dependent and long-term mechanical properties of concretes incorporating different grades of coarse recycled concrete aggregates. Engineering Structures 2018; 157: 224-234.

[24] Tabsh SW, Abdelfatah AS. Influence of recycled concrete aggregates on strength properties of concrete. Construction and Building Materials 2009; 23: 1163-1167.

[25] Matias D, de Brito J, Rosa A, et al. Durability of Concrete with Recycled Coarse Aggregates: Influence of Superplasticizers. J Mater Civ Eng 2014; 26: 06014011.

[26] Etxeberria M, Vázquez E, Marí A, et al. Influence of amount of recycled coarse aggregates and production process on properties of recycled aggregate concrete. Cement and Concrete Research 2007; 37: 735-742.

[27] Limbachiya MC, Marrocchino E, Koulouris A. Chemical-mineralogical characterisation of coarse recycled concrete aggregate. Waste Management 2007; 27: 201-208. 
[28] Limbachiya M, Meddah MS, Ouchagour Y. Use of recycled concrete aggregate in fly-ash concrete. Construction and Building Materials 2011; S0950061811003771.

[29] Silva RV, de Brito J, Dhir RK. Establishing a relationship between modulus of elasticity and compressive strength of recycled aggregate concrete. Journal of Cleaner Production 2016; 112: 21712186.

[30] Gomes M, de Brito J. Structural concrete with incorporation of coarse recycled concrete and ceramic aggregates: durability performance. Mater Struct 2009; 42: 663-675.

[31] Younis KH, Amin AA, Ahmed HG, et al. Recycled Aggregate Concrete including Various Contents of Metakaolin: Mechanical Behavior. Advances in Materials Science and Engineering 2020; 2020: $1-17$.

[32] Bui NK, Satomi T, Takahashi H. Mechanical properties of concrete containing $100 \%$ treated coarse recycled concrete aggregate. Construction and Building Materials 2018; 163: 496-507.

[33] Kou S, Poon C. Effect of the quality of parent concrete on the properties of high performance recycled aggregate concrete. Construction and Building Materials 2015; 77: 501-508.

[34] Wang Q, Geng Y, Wang Y, et al. Drying shrinkage model for recycled aggregate concrete accounting for the influence of parent concrete. Engineering Structures 2020; 202: 109888.

[35] Zhang H, Wang Y, Lehman DE, et al. Time-dependent drying shrinkage model for concrete with coarse and fine recycled aggregate. Cement and Concrete Composites 2020; 105: 103426.

[36] Bendimerad AZ, Delsaute B, Rozière E, et al. Advanced techniques for the study of shrinkageinduced cracking of concrete with recycled aggregates at early age. Construction and Building Materials 2020; 233: 117340 .

[37] ASTM C150 / C150M. Specification for Portland Cement. ASTM International. Epub ahead of print 2020. DOI: 10.1520/C0150_C0150M-20.

[38] ASTM C136 / C136M. Test Method for Sieve Analysis of Fine and Coarse Aggregates. ASTM International. Epub ahead of print 2019. DOI: 10.1520/C0136_C0136M-19.

[39] ASTM C29 / C29M. Test Method for Bulk Density (Unit Weight) and Voids in Aggregate. ASTM International. Epub ahead of print 2017. DOI: 10.1520/C0029_C0029M-17A.

[40] ASTM C127. Test Method for Relative Density (Specific Gravity) and Absorption of Coarse Aggregate. ASTM International. Epub ahead of print 2015. DOI: 10.1520/C0127-15.

[41] ASTM C128. Test Method for Relative Density (Specific Gravity) and Absorption of Fine Aggregate. ASTM International. Epub ahead of print 2015. DOI: 10.1520/C0128-15.

[42] Verian KP, Ashraf W, Cao Y. Properties of recycled concrete aggregate and their influence in new concrete production. Resources, Conservation and Recycling 2018; 133: 30-49.

[43] Limbachiya MC, Leelawat T, Dhir RK. Use of recycled concrete aggregate in high-strength concrete. Mat Struct 2000; 33: 574-580.

[44] ASTM C143 / C143M. Test Method for Slump of Hydraulic-Cement Concrete. ASTM International. Epub ahead of print 2020. DOI: 10.1520/C0143_C0143M-15A.

[45] EN B. 12350-4 Testing fresh concrete-Part 4: Degree of compatibility. Brit.Standards Institution.

[46] Gambhir ML. Concrete technology. New Delhi: Tata McGraw-Hill, 2006.

[47] Koehler EP, Fowler DW. Summary of concrete workability test methods. 2003

[48] EN B. 12390-3: 2019. Testing Hardened Concrete. Compressive Strength of Test Specimens; British Standard Institute: London, UK

[49] ASTM C78 / C78M. Test Method for Flexural Strength of Concrete (Using Simple Beam with Third-Point Loading). ASTM International.

[50] ASTM C496 / C496M. Test Method for Splitting Tensile Strength of Cylindrical Concrete Specimens. ASTM International. Epub ahead of print 2017. DOI: 10.1520/C0496_C0496M-17.

[51] ASTM C469 / C469M. Test Method for Static Modulus of Elasticity and Poissons Ratio of Concrete in Compression. ASTM International. Epub ahead of print 2014. DOI: 10.1520/C0469_C0469M-14.

[52] ASTM C157 / C157M. Test Method for Length Change of Hardened Hydraulic-Cement Mortar and Concrete. ASTM International. Epub ahead of print 2017. DOI: 10.1520/C0157_C0157M-17.

[53] Mehta PK, Monteiro PJM. Concrete: microstructure, properties, and materials. 3rd ed. New York: McGraw-Hill, 2006. 
[54] Dodds W, Goodier C, Christodoulou C, et al. Durability performance of sustainable structural concrete: Effect of coarse crushed concrete aggregate on microstructure and water ingress. Construction and Building Materials 2017; 145: 183-195.

[55] Ajdukiewicz A, Kliszczewicz A. Influence of recycled aggregates on mechanical properties of HS/HPC. Cement and Concrete Composites 2002; 24: 269-279.

[56] ACI Committee 318, American Concrete Institute. ACI 318-19: Building code requirements for structural concrete : ccommentary on building code requirements for structural concrete (ACI $318 R$ 19). Farmington Hills, MI: American Concrete Institute, 2019.

[57] Sanjuán MÁ, Andrade C, Mora P, et al. Carbon dioxide uptake by cement-based materials: A Spanish case study. Applied Sciences 2020; 10: 339.

[58] Hammond G, Jones C, Lowrie F, et al. Embodied carbon: the Inventory of Carbon and Energy (ICE). Bracknell: BSRIA, 2011.

[59] García-Segura T, Yepes V, Alcalá J. Life cycle greenhouse gas emissions of blended cement concrete including carbonation and durability. Int J Life Cycle Assess 2014; 19: 3-12. 